Article No 232

DOI: https://doi.org/10.26881/srg.2020.7.07

Citation:

Кирчанов, М. (2020). Имитация жанра жития в литературе

российского постмодернизма (на примере романа Владимира Шарова

«Будьте как дети»). Studia Rossica Gedanensia, 7: 88-99.

DOI: https://doi.org/10.26881/srg.2020.7.07

Kirčanov, M. (2020). Imitaciâ žanra žitiâ vliterature rossijskogo postmodernizma

(na primere romana Vladimira Šarova 'Bud'te kak deti'). Studia Rossica Gedanensia, 7: 88-99.

DOI: https://doi.org/10.26881/srg.2020.7.07

\title{
ИМИТАЦИЯ ЖАНРА ЖИТИЯ \\ В ЛИТЕРАТУРЕ РОССИЙСКОГО ПОСТМОДЕРНИЗМА (НА ПРИМЕРЕ РОМАНА ВЛАДИМИРА ШАРОВА БУДЬТЕ КАК ДЕТИ)
}

\author{
MАКСИМ КИРЧАНОВ / MAКSIM КIRCHANOV \\ Воронежский государственный университет / Voronezh State University \\ Факультет международных отношений / Faculty of International Relations \\ Кафедра регионоведения и экономики зарубежных стран / \\ Department of Regional Studies and National Economies \\ Пушкинская 16, 394000, г. Воронеж, Россия / Pushkinskaya st. 16, 394000 Voronezh, Russia \\ E-mail: maksymkyrchanoff@gmail.com \\ ORCID: https://orcid.org/0000-00033819-3103 \\ (Получено / Received 25.03.2020. Принято / Accepted 19.06.2020)
}

\section{Abstract \\ Imitation of Vita genre in the literature of Russian postmodernism (Vladimir Šarov's novel Bud'te kak deti)}

The author analyzes the features of imitation and simulation of the vita genre in the literature of Russian postmodernism in the contexts of Vladimir Šarov's novel Bud'te kak deti. It is concluded that 1) being a postmodernist writer, Vladimir Šarov only imitated and simulated religiosity; 2) Vladimir Šarov's prose can be interpreted in the 
categories of deconstruction of traditional identity and religiosity as one of its foundations; 3) Vladimir Šarov transplanted the main compositional and plot features of the vita genre into a postmodernist text for their further simultaneous deconstruction and (re)invention.

Key words: Vladimir Sharov, Bud'te kak deti, prose, vita, postmodernism, identity

\section{Резюме}

Автор анализирует особенности имитации и симуляции жанра жития в литературе российского постмодернизма в контекстах романа Владимира Шарова Будьте как дети. Предполагается, что 1) В. Шаров как писатель-постмодернист только имитировал и симулировал религиозность; 2) проза В. Шарова может быть интерпретирована в категориях деконструкции традиционной идентичности и религиозности как одного из ее оснований, 3) писатель трансплантировал основные композиционные и сюжетные особенности житий в постмодернистский текст для их деконструкции и (ре)изобретения одновременно.

Ключевые слова: Владимир Шаров, Будъте как дети, проза, житие, постмодернизм, идентичность

\section{Формулировка проблемы}

Постмодернизм в истории постсоветской литературы стал одним из течений, оказывавших значительное влияние на развитие основных векторов и направлений современной литературной истории. На протяжении 1990-х годов, после распада СССР и исчезновения советской литературы как модели развития русской литературы, постмодернизм в значительной степени претендовал не на уникальность, но на универсальность, что вынудило некоторых исследователей определять и воспринимать именно постмодернизм как универсальный культурный и эстетический код развития и функционирования всей постсоветской российской литературы на русском языке в целом, что сделало оценки и интерпретации сложившихся литературных ситуаций чрезвычайно общими и в ряде случаев аморфными. Поэтому такие разные по общей стилистике и содержанию текстов российские писатели, как В. Пелевин, В. Сорокин, Т. Кибиров и другие, почти автоматически определялись не только как постмодернисты, но и классики этого направления в России, что содействовало еще большей эрозии самой концепции «постмодернизма» и ее трансформации в родовое название для обозначения и описания гетерогенных ситуаций в российской постсоветской литературе. Среди постсоветских российских писателей-постмодернистов, которые пребывают в тени своих коллег, но тексты которых не менее значимы, особое место занимал Владимир Шаров (1952-2018) - фигура не столь популярная среди исследователей российского литературного постмодерна, но вместе 
с тем чрезвычайно важная для его литературного развития и интеллектуальной эволюции на протяжении 1990-2010-х годов.

\section{Особенности историографической ситуации}

Число исследований о наследии В. Шарова (Ащеулова 2016, Ащеулова 2014, Ащеулова 2013a, Ащеулова 2013b, Габриэлова 2015, Кірчанаў 2019), действительно, не столь значительно, как количество работ, сфокусированных на изучении текстов других российских писателей-постмодернистов, тем не менее его роль в развитии постмодерна не вызывает сомнений. Постмодернистская проза В. Шарова не просто воспроизводила на русском языке в отношении действительности все родовые особенности этого направления. Она предлагала качественно новую версию российской истории, основанную на ее радикальной ревизии в конструктивистской системе координат. Именно это позволяло писателю воспринимать участников российского исторического процесса как «воображаемые сообщества», а «узкие места» русской истории (мессианство, православие, большевизм, коммунизм) как ее «изобретенные традиции».

\section{Цель и задачи статьи}

В центре внимания автора данной статьи находится характеристика имитации житийного жанра как одной из особенностей российского постмодерна в понимании В. Шарова в контекстах его романа Будьте как дети (Шаров 2008a, Шаров 2008b, Шаров 2017). Целью статьи является анализ использования житийного приема в литературе российского постмодерна на примере романа Будьте как дети, а задачами - анализ особенностей трансплантации и деконструкции, изучение основных закономерностей функционирования, мутации и адаптации житийного жанра в контекстах исторического воображения литературы постмодернизма.

Шаров в своей прозе трансплантировал основные положения житийного жанра, адаптируя их к постмодернистскому дискурсу. В романе Будьте как дети писатель использовал житийную парадигму дважды: с одной стороны, в сюжетной линии, связанной с «энцским апостолом Павлом - Евлампием Христофоровичем Перегудовым» (Шаров 2017: 68), с другой - в «ленинской» части романа. Если описание истории Перегудова подчинено логике жития в целом, то «житийные» моменты в версии биографии В.И. Ленина в романе Шарова актуализирует в большей степени потенциал мученичества.

\section{Житие: религиозный текст}

В романе Будьте как дети Шаров трансплантирует в авторский нарратив писателя начала XXI века основные характеристики и особенности религиозного жития как жанра. 
Если многие средневековые жития начинались с полумифических преданий о появлении будущего святого, то появление одного из героев романа, Перегудова, среди энцов было связано с «чудом» побега от российского общества XIX века, что сопровождалось многочисленными грехами будущего «апостола», который убил нескольких человек. В этом контексте Шаров также копирует законы развития житийного жанра в силу того, что путь к святости некоторых героев средневековых житий был отягощен как грехами, так и преступлениями. Если в ряде житий женщина была причиной прегрешений будущего святого, то Шаров использовал и этот прием:

У Перегудова уже была зазноба, разбитная солдатка Катя - баба красивая и молодая. Катя и свела егослихими людьми». Писатель успешно трансплантировал это клише религиозной литературы в постмодернистский текст. Если авторы некоторых средневековых житий перечисляют прегрешения будущего святого, чтобы показать значимость его спасения, то В. Шаров использовал и эту особенность: «Перегудов говорил энцам, что он просто бежал, куда угодно, лишь бы спастись от нового душегубства. Но чем дальше он уходил, тем больше было крови» (Шаров 2017: 73-74).

Шаров, таким образом, имитировал закономерности построения текста и развития сюжета жития, но уже в качественно иной, постмодернистской, системе координат. Писатель трансплантировал в постмодернистский контекст и другие родовые травмы житийной литературы, включая временное просветление героя - «он аккуратно исполнял свои обязанности... читал Священное писание, молился и спал» (Шаров 2017: 78) - перед его новыми грехами. В то время как тексты классических житий содержат идеологически выверенные и политически необходимые сцены и описания падения язычества, роман Шарова актуализирует аналогичные мотивы - «лишь к вечеру шаман изнемог, ноги его подкосились, и, повалившись на землю, он начал биться в агонии. Было видно, как изо рта Ионаха вместе с пеной уходят последние капли жизни» (Шаров 2017: $93)$ - интегрированные в большей степени в момент исторического кризиса и гибели традиционного общества. Традиция и архаика в романе Будьте как дети являются важными и смыслообразующими элементами нарратива о традиционном обществе как «золотом веке», когда «меньше двух поколений назад они свободно бродили по тундре... они владели, были хозяевами огромных и бескрайних пространств... они знали как возник этот мир» (Шаров 2017: 96), но христианизация как форма модернизации фактически разрушает основания такой традиционной идентичности в силу того, что русские играют роль сообщества, которое не только христианизирует, но модернизирует их, вынуждая узнать и понять, что «все это не более чем красивая сказка. Никакого Охона нет и никогда не было, и они не избранный его народ, а мелкие, жалкие дикари, слабые, ущербные людишки» (Шаров 2017: 96).

Поэтому христианизация как модернизация в романе Будьте как дети становится одновременно вынужденным и насильственным взрослением, концом детства как «золотого века» традиционного общества. Если многочисленные тексты житийного жанра в качестве одного из центральных сюжетов имеют чудесное обретение святого, то роман Шарова Будьте как дети имитирует и этот 
момент поэтики житийного жанра потому, что будущего святого «подобрали на песке, у кромки камышей, он был в бессознательном состоянии, подолгу бредил... был совсем плох, и они не думали, что он выживет» (Шаров 2017: 88). «Конструируя» биографию Перегудова, Шаров деконструирует не только законы развития житийного жанра, но и подвергает ревизии основные мифы как советской русской литературы, так и историографии, что относится в первую очередь к революции (Шаров 2017: 70) как коллективному месту памяти. Трансплантируя родовые травмы жития в постмодернистский роман, Шаров не только использует потенциал традиционной поэтики архаичной культуры.

В ходе анализа текста романа Будьте как дети становится очевидно, что Шаров не только имитировал и симулировал законы житийного жанра, но фактически соединял их с закономерностями развития и функционирования другого политически и идеологически мотивированного жанра - революционной биографии, столь характерной для советской прозы социалистического реализма. В этом контексте Шаров одновременно симулирует и имитирует житие традиционное (религиозное) и модерное (политически-революционное), что фактически актуализирует значение романа Будьте как дети как текста-цитаты, текста-конструкта и текста, основанного на смешении формально противоположных жанров - религиозного жития и фактически политического романа. Деконструируя житийные мотивы, Шаров подвергает ревизии и родовые травмы массовой литературы, подвергая маргинализации романтический пафос более ранней русской литературной традиции, сводя глорификацию насилия к его обыденному описанию, что заставляет героя фактически смириться с тем, что «он порешит десять человек, причем убьет их легко, безо всякого сожаления, будто кур зарежет» (Шаров 2017: 72).

Трансплантируя особенности жития в постмодернистский текст, Шаров стремится одновременно зафиксировать особенности традиционного сознания и деконструировать их. Например, энцы, этническая группа воображенная и изобретенная Шаровым, описываются, с одной стороны, как носители традиционной идентичности, которые в проповеди бывшего солдата Перегудова руководствовались буквализмом («слова Перегудова, даже не соглашаясь с ними, самодийцы до последних лет сохраняли с большой тщательностью. Они верили, что ничего лишнего, неважного в его рассказах нет и быть не может» (Шаров 2017: 69)), так как не могли осмыслить им сказанное в другой системе координат. С другой стороны, Шаров активно конструировал особенности идентичности, характерные именно для традиционного общества, которое развивалось не в либроцентричной системе координат, так как его идентичность имела вербальные основания, и поэтому «проповеди Перегудова почти пятьдесят лет передавались единственным способом - из уст в уста» (Шаров 2017: 70).

Примечательно и то, как постмодернистский текст подвергает ревизии основы христианства, деконструирует их из ближневосточного контекста и трансплантирует в тундру позднего имперского или советского периода - поэтому «в перегудовской редакции Библии никто, поя овец, не отваливал камень и не рыл колодцев, и вместо пажитей с сочной травой были богатые ягелем болота. Молитва, обращенная к Всевышнему, отгоняла безжалостных волков, ветер 
сносил тучи гнуса, и олени - не овцы, - пасясь сытно и спокойно, каждую весну приносили богатый приплод» (Шаров 2017: 97).

В этом контексте постмодернистский роман, с одной стороны, фактически становится фактором модернизации и национализации христианства, приписывания статуса «избранного народа Божьего» (Шаров 2017: 100). С другой, не менее важно и то, что энцы, анонимные герои романа, вынужденно принимают правила игры современного общества и поэтому выступают в качестве почти модернистских конструкторов, которые «начали энергично править его рассказы. Любые намеки на вину... безжалостно ими вымарывались... той же цензуре подвергли и последнее убийство, которое произошло... на их глазах. В канонической версии... всю вину за смерть шамана... они берут на себя» (Шаров 2017: $89)$, то есть фактически подвергают ревизии и цензуре историческую и культурную память своего сообщества.

\section{Житие: политический текст}

Постмодернистскому роману, в той версии в которой его стремился писать Шаров, было явно тесно с рамках традиционных форм - поэтому писатель активно симулировал и имитировал те литературные жанры, которые доминировали ранее, вырывая известных героев из не менее известных и ставших классическими реалий, помещая их в те условия и обстоятельства, которые были явно несовместимы с политически и идеологически мотивированными требованиями более ранней литературной традиции, что в полной мере относится к попытке Шарова в романе Будьте как дети совместить и синтезировать нормы жития, политической биографии и такого явления советской литературы как «лениниана».

Украинский историк Ирына Колэснык, комментируя отношения профессионального исторического сообщества с властью, полагает, что возможно несколько вариантов взаимодействия интеллектуалов и политического режима. Поэтому «историк всегда находится в силовом поле политики и власти. Одни историки сознательно обслуживают потребности власти, как официальные историографы правителей, династий, стран, даже выступают архитекторами новых государств. Другие не демонстрируют открыто своих политических предпочтений и взглядов. Некоторые сознательно отстраняются от власти и государственных институтов, ведь настоящий интеллектуал всегда находится в оппозиции к власти и существующему режиму» (Колесник 2017: 9).

В этой ситуации показательна та тактика, выбор в пользу которой сделал профессиональный историк Шаров. Несмотря на опыт работы в академическом институте и защиту кандидатской диссертации, ему было тесно в рамках того диапазона возможностей, который предлагала академическая историография. Поэтому литература стала попыткой сознательного отстранения как от власти, так и от формальных требований академического дискурса - проза давала гораздо больше возможностей конструирования, воображения и изобретения прошлого. Хотя конструктивистский поворот, начавшийся в российской исто- 
рической науке в 1990-е годы, обеспечивал историков аналогичными возможностями, литература, тем не менее, с точки зрения внутренней свободы была все же более привлекательной.

Если «житие» Евлампия Перегудова актуализирует основные закономерности и особенности развития жанра, характерные для религиозных житий, то часть романа, сфокусированная на последних годах жизни В.И. Ленина, в большей степени апеллирует к мученичествам, являясь фактически попыткой деконструкции советского идеологически и политически мотивированного канона ленинского жития с заменой его новым нарративом, явно локализованным в системе координат, основанной на имитации и симуляции религиозного сознания. Шаров - не первый российский интеллектуал, который пытается деконструировать ленинский миф из русской идентичности: его попыткам предшествуют как политически поддерживаемые и санкционированные стратегии формирования этого мифа (Шагинян 1977, Пискунов 1970), так и отдельные попытки его ревизии и деконструкции (Тумаркин 1997).

Версия ленинского жития в прозе Шарова стала не только попыткой пересмотра и ревизии истории, но и трансформациями в функционировании и воспроизводстве исторической и культурной памяти в постсоветской России. Если в советский период память цензурировалась и регламентировалась, автоматически исключая альтернативные объяснения и интерпретации, то падение коммунистических режимов и связанных с ними стратегий работы с памятью вдохновило «пересмотр прошлого, который произошел после краха коммунизма, частично от того, что коммунистический период воспринимался как какаято эрозия памяти в „режиме забывания” (Аўтўэйт, Рэй 2006: 29). «Забывание» стало не только универсальной моделью функционирования исторической и культурной памяти в транзитных обществах (где восприятие истории и прошлого было отягощено как политическими мифами, так и идеологическими стереотипами), но оно также стимулировало процессы конструирования новых версий памяти: «если прошлое воспринимается как негативное... и отклонение от „нормального” пути, то перед... обществом встает задача прощания с наследием и преодоления негативного опыта, исправления собственной траектории развития» (Ластоўскі 2016: 37).

В этой ситуации взрыв исторической памяти, который фактически привел к росту исторического мифотворчества, актуализировал «санитарные» функции литературы как части исторической памяти. Поэтому в прозе Шарова конструирование новых исторических мифов через отрицание и деконструкцию советской политически и идеологически мотивированной эстетики «изобретения» Ленина в рамках «высокой» советской культуры и «обращение к прошлому является результатом стремления к терапевтической коррекции настоящего путем нарушения прошлого опыта и его трансформированного перехода к настоящему» (Кръстев 2003). Поэтому альтернативные попытки воображения истории, даже если они не имели отношения к историческим реалиям прошлого, воспринимались интеллектуалами как попытка вообразить «нормальный» путь истории, что фактически стало попыткой избавиться от политических и культурных травм советского прошлого. Падение коммунизма освободило 
интеллектуалов от необходимости формировать нарративы в рамках идеологически и политически мотивированного канона, активизировав коллективную память и заставив ее работать в режиме «вспоминания», точнее - нового воображения, изобретения, конструирования истории и наделения ее теми смыслами, которые предыдущими поколениями интеллектуалов не прочитывались или игнорировались.

Анализируя особенности развития ленинианы в прозе Шарова, следует брать во внимание не только ее ревизионистский характер, но и то, «против» чего направлена эта ревизия. С одной стороны, Шаров подвергает пересмотру и, как следствие, деконструкции классические советские версии изобретения и воображения образа Ленина (Драбкина 1961, Воскресенская 1972, Шагинян 1959, Катаев 1965), выдержанные в идеологически и политически мотивированной системе координат. С другой стороны, Шаров явно не проявляет солидарности и с антисоветскими попытками формирования образа Ленина (Солженицын 1975, Ерофеев 2001) - и первые, и вторые деконструируются им в одинаковой степени. Кроме этого, шаровская версия ленинианы основана также на сомнении в отношении тех образов Ленина, которые сами по себе были ревизионистскими, предложенные в российской литературе 1990-х годов (Пелевин 2005). В одинаковой степени скептическое отношение Шарова к своим предшественникам, которые писали о Ленине, позволяет некоторым исследователям подчеркивать, что «роман находится... посередине парадигмы, представляя мейнстрим, стремящийся к объективной характеристике времени, соблюдении дистанции, исторической персонализации, поскольку соединяет как утопию советского времени, так и антиутопию постсоветского периода» (Лихина 2009), хотя, как полагает автор в этой статье, для текста В. Шарова в большей степени был характерен не синтез, а склонность к конструкции нового мифа через деконструкцию предыдущего.

Если Ленина в СССР «не изучали, имелись процедуры ритуального цитирования» (Кожокин 2014), если в советской литературе фигуру Ленина канонизировали, то современные интеллектуалы склонны предлагать альтернативные версии, основанные на деконструкции более раннего канона. Поэтому воображаемое и конструируемое «житие» Ленина в романе Шарова Будьте как дети обладает несколькими особенностями. Житие Ленина, по версии Шарова, - это не просто памятник агиографии и не мученичество. Поэтому Шаров предлагает ревизионистское восприятие ленинской биографии, словно намеренно деконструируя раннее возникшие и утвердившиеся историографические и литературные мифы. В этом отношении Шаров не только писатель, но и профессиональный историк, который не избегает использования ревизионизма. Американский историк Джэймс МакФерсон, комментируя роль ревизии в развитии исторического знания, подчеркивает, что именно она «является жизненной основой исторической науки» (McPherson 2003: 1). Поэтому, деконструируя ранние историографические, литературные и политические мифы о Ленине, Шаров не только их извлекает из культурного и интеллектуального контекста эпохи, но фактически предлагает их альтернативную конструкцию. 
Традиционно «житие» в литературе может быть определено как жанр фиксированный, в романе же Шарова различные герои являются носителями разных версий ленинского жития, причем это житие передается не письменно, но устно, что в определенной степени приближает его к традиционной культуре. Ленин в прозе Шарова - это Ленин-конструкт, Ленин-ревизия более ранних образов, созданных в советской литературе. В романе Будьте как дети Ленин, который отрицает Бога, спорит с ним и одновременно стремится к нему, предстает как вождь религиозного движения - «всероссийского похода детей в Святую землю», крестового похода и крестного хода «коммунаров» одновременно. Поэтому ленинский террор интерпретируется в категориях Страшного Суда и будущего спасения, а сам Ленин в определенной степени уподобляется Ивану Грозному оба предстают как тираны, которые через террор против «безгрешных и невинно убиенных... тельцов без изъяна и порока» пытались приблизить пришествие Царства Божьего для «нового святого народа» (Шаров 2017: 130, 165, 173, 189).

В прозе Шарова коммунистический террор и насилие конструируются через симуляцию и имитацию религиозных образов - поэтому репрессии в литературном и историческом воображении писателя воспринимаются как условия для спасения, а новый избранный народ изобретается как «творцы переходных форм к коммунистическому строю», которые «были необходимы», так как «без нас не пришли бы другие, те, кто уже - сам коммунизм». Если для советских авторов официальных биографий как аналога «житий» Ленин был фигурой в значительной степени мифологизированной, то у Шарова Ленин, наоборот, демифологизирован, но через его интеграцию в религиозный канон. Поэтому у Шарова Ленин - революционер в прошлом, но в событиях, описанных в романе, это Ленин, который понимает, что «единственное назначение слов - думать о Боге и с Богом говорить», и поэтому он «много думает о Боге... неотрывно думает о Боге. О самом Господе, а не о церкви», потому что «на путях промысла Божия роль Ленина по-прежнему велика, и Господь его не забывает» (Шаров 2017: 116, 121, 141, 143).

\section{Выводы}

Использование элементов житийного жанра никогда не входило в число основных литературных приемов Шарова, но встречалось исключительно в контекстах воображения и конструирования истории и образов прошлого, симуляции и имитации исторического нарратива. Историк по образованию, кандидат исторических наук, знавший методы внутренней и внешней критики источника, много работавший в архивах, Шаров умел очень тонко и соответствующим образом имитировать особенности текста источника, сочетая их с симуляцией академического дискурса, что придает его прозе характер текстов-конструктов. Это в полной мере относится и к житийным мотивам в романе Будьте как дети.

Шаров имитирует те приемы, которые традиционно использовались в средневековой житийной литературе, одновременно деконструируя и демонтируя религиозно-центричный канон и трансплантируя его основные положения 
в дискурс литературы постмодернизма. Шаров как профессиональный историк не лишает себя удовольствия использовать в фактическом тексте-конструкте приемы внутренней и внешней критики им же изобретенного источника. Если «житие» Евлапмия Перегудова в романе Будьте как дети строится на принципах житийного жанра, на трансплантации и переносе общих мест из многочисленных средневековых житий в текст постмодернистского романа, то «житийные» страницы этого произведения сопровождаются симуляцией почти академической интерпретации. Житие в прозе Шарова становится одной из многочисленных форм перформанса, минимизируя историю в целом до игры, а события в частности до симулякров, которые одновременно и уникальны, и серийны.

Шаров трансплантировал в текст фактически все «общие места» житийной литературы, включая чудесное появление героя, искупление им собственных грехов, многочисленные совершенные прижизненные чудеса, центральным из которых было обращение ранее языческого народа в христианство. Созданная Шаровым версия «жития» была бы неполной, если бы он не сопроводил ее внешними легитимациями, включая многочисленные воспоминания и впечатления как современников, так и потомков о герое «жития», хотя и сам герой, и претендующие на аутентичность исторического источника свидетельства являются не более чем конструктами, которые имитируют реальность, воображая и изобретая ее. Кроме этого, имитация «жития» как жанра написания истории имела принципиальное значение для развития исторического воображения в прозе Шарова.

Традиционно в историографии житие воспринимается как жанр, в значительной степени архаичный и фактически не соотносящийся с современной культурой. Шаров в своей прозе уподобляет историю фронтиру, что допускает и позволяет одновременное сосуществование и софункционирование как архаического, так и модернового сознания. Используя в своих текстах имитации и симуляции различных типов источников - от жития до письма, от официального документа до богословского сочинения - Шаров, с одной стороны, демифологизирует и десакрализирует источник, а с другой - «расшифровывает» саму историю, наделяя ее смыслами и значениями как конструктами, что позволяет их деконструировать, превращая историю, мифологизированную и идеологизированную предыдущими поколениями как историков, так и писателей, в один из многочисленных конструктов и симулякров литературы постмодернизма.

Специфика российского постмодернизма в прозе Шарова не ограничивается только теми сюжетами, которые были проанализированы в настоящей статье. Роман Будьте как дети содержит различные модификации житийного жанра, трансплантированные в такой политически и идеологически мотивированный сюжет российской исторической и политической памяти, как русская революция и роль Ленина, что указывает на необходимость дальнейшего изучения постмодернистского переосмысления житийной парадигмы как одной из форм конструирования постмодернистского текста и функционирования исторического воображения. 


\section{Библиография / References}

Aŝeulova, I.V. (2013a). Semejnaâ hronika kak formirovanie istoričeskoj pamâti pokolenij v romane V. Šarova „Sled v sled”. Vestnik Tomskogo gosudarstvennogo pedagogiceskogo universiteta, 2 (130): 48-53 [Ащеулова, И.В. (2013a). Семейная хроника как формирование исторической памяти поколений в романе В. Шарова «След в след», Вестник Томского государственного педагогического университета, 2 (130): 48-53].

Aŝeulova, I.V. (2013b). Sûžet poiska pravdy kak osuŝestvlenie mečty o rae na zemle v proze V. Šarova. Sûžetologiâ $i$ sûžetografiâ, 2: 72-78 [Ащеулова, И.В. (20136). Сюжет поиска правды как осуществление мечты о рае на земле в прозе В. Шарова. Сюжетология и сюжетография, 2: 72-78].

Aŝeulova, I.V. (2014). Trud duši čeloveka kak sohranenie istoričeskoj pamâti roda v romanah V. Šarova. Vestnik Kemerovskogo gosudarstvennogo universiteta, 3/1 (59): 162-166 [Ащеулова, И.В. (2014). Труд души человека как сохранение исторической памяти рода в романах В. Шарова. Вестник Кемеровского государственного университета, 3/1 (59): 162-166].

Aŝeulova, I.V. (2016). Sûžet „vtoroe prišestvie Hrista” v romanah V. Šarova. Sibirskij filologičeskij žurnal, 2: 106-113 [Ащеулова, И.В. (2016). Сюжет «второе пришествие Христа» в романах В. Шарова. Сибирский филологический журнал, 2: 106-113].

Aǔtǔèjt, Ǔ., Rèj, L. (2006). Madèrnasc', pamâc' ì postkamunìzm. Palityčnaâ sfera, 6: 27-43 [Аўтўэйт, Ў., Рэй, Л. (2006). Мадэрнасць, памяць і посткамунізм. Палітычная сфера, 6: 27-43].

Voskresenskaâ, Z.I. (1972). Parol' - Nadežda. Moskva: Detskaja literatura [Воскресенская, 3.И. (1972). Пароль - Надежда. Москва: Детская литература].

Gabrièlova, A. (2015). Filosofsko-istoričeskij grotesk v romane „Vozraŝenie v Egipet” Vladimira Šarova. Voprosy literatury, 3: 177-185 [Габриэлова, А. (2015). Философско-исторический гротеск в романе «Возращение в Египет» Владимира Шарова. Bonросы литературы, 3: 177-185].

Drabkina, E. (1961). Černye suhari: rasskazy. Moskva: Sovetskij pisatel' [Драбкина, Е. (1961). Черные сухари: рассказы. Москва: Советский писатель].

Erofeev, V.V. (2001). Sobranie sočinenij. T. 2: Zapiski psihopata. Blagaâ vest'. Proza iz žurnala „Veče”. Moâ malen'kaâ leniniana. Interv'û. Iz zapisnyh knižek. Moskva: Vagrius [Ерофеeв, B.B. (2001). Собрание сочинений. Т. 2: Записки психопата. Благая весть. Проза из журнала «Вече». Моя маленькая лениниана. Интервью. Из записных книжек. Москва: Вагриус].

Kataev, V.P. (1965). Malen'kaâ železnâ̂ dver'v stene. Moskva: Sovetskij pisatel' [Катаев, В.П. (1965). Маленькая железная дверь в стене. Москва: Советский писатель].

Kìrčanaǔ, M.V. (2019). Topas ruhu âk pastâ̂nnaga vârtannâ ǔ prozeruskaga ì belaruskaga postmadèrnizmu (na prykladze tèkstaǔ Uladzìmira Šarova ì Viktara Marcìnoviča). V: Arcâmënak, H.A. (Red.). Bielaruskaja mova i litaratura ŭ slavianskim etnakulturnym kantekscie. Vìcebsk: VDU ìmâ P.M. Mašèrava: 166-169 [Кірчанаў, M.В. (2019). Топас руху як пастаяннага вяртання ў прозе рускага і беларускага постмадэрнізму (на прыкладзе тэкстаў Уладзіміра Шарова і Віктара Марціновіча). В: Арцямёнак, Г.А. (Рэд.). Беларуская мова і літаратура у славянскім этнакультурным кантэксие. Віцебск: ВДУ імя П.М. Машэрава: 166-169].

Kožokin, Е. (2014). Politika i antipolitika v sud'be istorika. „Put'vverh $i$ vniz odin $i$ tot že”. M.Â. Gefter v vospominaniâh druzej $i$ očevidcev. (Online) http://gefter.ru/archive/13678 (dostup 2.02.2020) [Кожокин, Е. (2014). Политика и антиполитика в судьбе историка. «Путь вверх и вниз один и тот же». М.Я. Гефтер в воспоминаниях друзей и очевидиев. (Online) http://gefter.ru/archive/13678 (доступ 2.02.2020)]. 
Kolesnik, I. (2017). Ukraïns'kij ìstorik ì vlada: vìd primusu do partnerstva. Ejdos, 9: 9-24 [Колесник, I. (2017). Український історик і влада: від примусу до партнерства. Ейдос, 9: 9-24].

Kr"stev, D. (2003). Kanon i/ili agon. Literaturnoistoričeskite (re)konstrukcii. V: Vačeva, A., Čobanov, G. (Red.). Kultura i kritika. T. 3: Kraât na modernostta? Varna: LiterNet: 416-449 [Кръстев, Д. (2003). Канон и/или агон. Литературноисторическите (ре)конструкции. В: Вачева, А., Чобанов, Г. (Ред.). Култура и критика. Т. 3: Краят на модерността? Варна: LiterNet: 416-449].

Lastoǔskì, A. (2016). Prapracoǔka kamunìstyčnaga mìnulaga ǔ Slavakì̀: asnoǔnyâ faktary ì dynamika faktary i dynamika. Palityčnâ̂ sfera, 24: 37-55 [Ластоўскі, А. (2016). Прапрацоўка камуністычнага мінулага ў Славакіі: асноўныя фактары і дынаміка. Палітычная сфера, 24: 37-55].

Lihina, N.E. (2009). Utopičeskij aspekt romana V. Šarova „Bud’te kak deti”. Vestnik RGU im. I. Kanta, 8: 87-90 [Лихина, Н.Е. (2009). Утопический аспект романа В. Шарова «Будьте как дети». Вестник РГУ им. И. Канта, 8: 87-90].

McPherson, J. (2003). Revisionist Historians. Perspectives on History, 41 (6): 1.

Pelevin, V. (2005). Vse rasskazy. Moskva: Eksmo [Пелевин, В. (2005). Все рассказы. Москва: Эксмо].

Piskunov, V.M. (1970). Sovetskaâ Leniniana: obraz V.I. Lenina v sovetskoj literature. Moskva: Hudožestvennaâ literatura [Пискунов, В.М. (1970). Советская Лениниана: образ В.И. Ленина в советской литературе. Москва: Художественная литература].

Solženicyn, A.I. (1975). Lenin v Cûrihe. Paris: YMCA-Press [Солженицын, А.И. (1975). Ленин в Цюрихе. Paris: YMCA-Press].

Tumarkin, N. (1997). Lenin živ! Kul't Lenina v Sovetskoj Rossii. Sankt-Peterburg: Akademičeskij proekt [Тумаркин, Н. (1997). Ленин жив! Культ Ленина в Советской России. Санкт-Петербург: Академический проект].

Šaginân, M. (1959). Semầ Ulânovyh: Očerki. Stat'i. Vospominaniâ. Moskva: GIHL [Шагинян, M. (1959). Семья Ульяновых: Очерки. Статьи. Воспоминания. Москва: ГИХЛ].

Šaginân, M.S. (1977). Leniniana. Moskva: Molodaâ gvardiâ [Шагинян, M.С. (1977). Лениниана. Москва: Молодая гвардия].

Šarov, V.A. (2008a). Bud'te kak deti. Moskva: Vagrius [Шаров, В.А. (2008a). Будьте как дети. Москва: Вагриус].

Šarov, V.A. (2008b). Bud’te kak deti, Znamja, 1-2 [Шаров, B.A. (2008b). Будьте как дети, Знамя, $1-2]$

Šarov, V.A. (2017). Bud'te kak deti. Moskva: AST - Redakciâ Eleny Šubinoj [Шаров, B.A. (2017). Будьте как дети. Москва: АСТ - Редакция Елены Шубиной].

Competing interests: The author declares that he has no competing interests. 